Arq. Bras. Med. Vet. Zootec., v.67, n.6, p.1639-1645, 2015

\title{
Caracterização bioquímica e molecular de Cryptococcus spp. isolados de excretas ambientais de pombos (Columba livia domestica)
}

\author{
[Biochemical and molecular characterization of Cryptococcus spp. isolates from environmental \\ feces of pigeons (Columba livia domestic)] \\ G. Colombo, C.V. Táparo, E.C. Araújo Júnior, M.Y. Makatu, F.S. Santos, M. Marinho* \\ Faculdade de Medicina Veterinária de Araçatuba - FMVA- Unesp, Araçatuba, SP
}

\begin{abstract}
RESUMO
Os pombos possuem uma rica diversidade de microrganismo, entre eles fungos sapróbios, como do gênero Cryptococcus, que podem atuar como agentes patogênicos para o homem e animais. Objetivou-se o isolamento, a caracterização bioquímica e a molecular de amostras de Cryptococcus spp. de excretas ambientas de pombos. Foram colhidas 100 amostras ambientais de pontos equidistantes e representativos da área da cidade de Araçatuba, São Paulo. As amostras foram rasteladas do solo de vias públicas, armazenadas em frasco coletor e encaminhadas para o Laboratório de Bacteriologia e Micologia da FMVA, onde foram processadas e cultivadas em duplicata, em placas de Petri contendo ágar Sabouraud dextrose a $4 \%$ e Niger. Em seguida, foram incubadas à temperatura ambiente e a $30^{\circ} \mathrm{C}$, respectivamente, por um período não inferior a 15 dias. Após a observação diária, as colônias sugestivas para levedura foram reisoladas em ágar Niger e submetidas a testes bioquímicos para posterior caracterização molecular pela técnica da PCR. Como resultado, a caracterização bioquímica e a molecular isolaram 32 colônias leveduriformes, sendo $8 \%$ dos cultivos positivos para Cryptococcus neoformans var. neoformans, $17 \%$ para Rhodotorula rubidae e 7\% Candida albicans. Pelo exposto, concluiu-se que excretas ambientais de pombos constituem um microfoco para Cryptococcus neoformans var. neoformans e outras leveduras com potencial patogênico, representando um risco à saúde pública, sendo necessárias medidas preventivas, como a higienização com a correta remoção das excretas, a fim de minimizar os riscos de exposição ambiental.
\end{abstract}

Palavras-chave: Cryptococcus neoformans, pombos, bioquímico, PCR, saúde pública

\begin{abstract}
Pigeons have a rich diversity of microrganisms, including fungi saprobes such as the genus Cryptococcus that can act as a pathogen for humans and animals. The aim of this was their isolation, biochemical and molecular characterization of samples of Cryptococcus from ambientas avian excreta. One hundred environmental samples, representative of the area equidistant from Araçatuba, São Paulo points were collected. The samples were removed and stored in collection bottles, sent to the Laboratory of Bacteriology and Mycology of FMVA, where they were processed and cultivated in duplicate on Petri dishes containing Sabouraud dextrose $4 \%$ and Niger and incubated at room temperature $30^{\circ} \mathrm{C}$, respectively, for a period of no less than 15 days. Colonies after daily observation which were suggestive for yeast growth were re-isolated in Niger agar and subjected to biochemical analisis for further molecular characterization by PCR tests. As results, the biochemical and molecular characterization of 32 yeast colonies revealed $8 \%$ of cultures positive for Cryptococcus neoformans var. neoformans, $17 \%$ Rhodotorula rubidae and 7\% Candida albicans. It was concluded that environmental avian excreta are active sites for replication of Cryptococcus neoformans var. neoformans and other yeasts with pathogenic potential. These constitute a public health risk, and preventive measures are necessary, such as cleaning and complete removal of excreta in order to minimize the risk of environmental exposure.
\end{abstract}

Keywords: Cryptococcus sp, pigeons, biochemist, PCR, public health

Recebido em 13 de junho de 2014

Aceito em 17 de agosto de 2015

*Autor para correspondência (corresponding author)

E-mail: mmarinho@fmva.unesp.br 


\section{INTRODUÇÃO}

A criptococcose constitui uma enfermidade fúngica leveduriforme que acomete o homem e os animais. Trata-se de espécie heterogênea, podendo ser diferenciada por características bioquímicas, antigênicas e epidemiológicas, distinguindo-se por duas variedades e cinco sorotipos (C. neoformans var. neoformans, sorotipos A, D e AD; C. neoformans var. gattii, sorotipos B e C). O Cryptococcus neoformans é um importante agente zoopatogênico cosmopolita e representa, na atualidade, a principal causa de meningoencefalite em hospedeiros com imunodepressão celular, cujo maior contingente é representado por indivíduos com Aids (Fortes et al., 1999). O C. neoformans variedade gattii, com sorotipos B e C, ocorre em regiões tropicais e subtropicais e comporta-se como patógeno primário, acometendo pacientes imunocompetentes (Know-Chung e Bennet et al., 1994). Em vegetais, foi inicialmente isolado em 1990 por Ellis e Pfeifer (1990), associado a espécies de Eucaliptus camaldulensis e posteriormente relacionado a outras espécies vegetais, como Cássia grandis, Senna multijuga e Fícus microcarpa, indicando novas fontes naturais para o fungo (Queiroz et al., 2008). A infecção pode ocorrer pela inalação de propágulos de origem ambiental (Levitz, 1991), representados por leveduras desidratadas, menores que $2 \mathrm{~mm}$ de diâmetro, facilmente aerossolizadas (Filiú et al., 2002), presentes em locais contaminados por fezes secas, bem como pela ingestão de poeira e/ou alimentos contaminados com as excretas de aves. Os indivíduos infectados podem desenvolver dermatites, problemas respiratórios ou até mesmo ter o sistema nervoso central acometido (Silva e Capuano, 2008).

$\mathrm{Na}$ maioria das vezes, as infecções são esporádicas e ocasionais, porém alguns surtos epidêmicos foram descritos em grande número de animais (Torres-Rodrigues et al., 2006). Nos últimos 20 anos, a incidência de infecções humanas causadas por leveduras, principalmente C. neoformans e Candida spp., tem aumentado em pessoas expostas a excrementos de aves (Maia, 2009). Entre as aves sinantropicas, o pombo (Columba livia domestica), ave exótica de origem europeia, introduzida no Brasil no século XVI, apresenta grande interesse em saúde pública (Queiroz et al., 2008). Por ter se disseminado amplamente em áreas urbanas e por ser manso, adaptou-se bem em locais onde há facilidade de alimento e abrigo, coabitanto áreas de grande aglomerado populacional, principalmente telhados de escolas, hospitais e praças.

Alguns autores têm descrito a presença do Cryptococcus neoformans var. neoformans em excretas de pombos em igrejas, ruas e praças, enfatizando o provável risco ao público (Filiú et al., 2002). Apesar do baixo isolamento desse agente em locais públicos no presente estudo, a situação precária de higienização desses locais pode propiciar a infecção inclusive de outros fungos leveduriformes de caráter oportunista. Sabe-se que as aves têm um importante papel na contaminação ambiental e na manutenção de agentes fúngicos devido à presença de compostos nutritivos em suas fezes. A variedade neoformans, $\mathrm{A}, \mathrm{AD}$ e $\mathrm{D}$, tem a capacidade de colonizar a mucosa do papo dos pombos, sem causar a doença, comportando-se como agente endossaprófito natural dessas aves (Filiú et al., 2002), sendo eventualmente excretada para o meio ambiente. Pela ação do ar, os propágulos aerossolubilizados contaminariam excretas de pombos não contaminados (Casadevall e Perfect, 1998). O isolamento de Cryptococcus spp. de excretas de psitacídeos (Filiú et al., 2002), passeriformes (Marinho et al., 2010) e morcegos (Tencate et al., 2012) tem sido relatado constantemente na literatura e muitas vezes associado ao hábito da ave de raspar e fragmentar pedaços de madeira e galhos (Filiú et al., 2002).

Destaca-se ainda que outras leveduras, correlacionadas com potencial patogênico, podem ser isoladas de excreções, como Candida, Rhodotorula, Trichosporon e Saccharomyces (Maia, 2009). As espécies de Rhodotorula, apesar de estarem amplamente distribuídas na natureza, nas duas últimas décadas surgiram como agentes oportunistas, particularmente em pacientes imunossuprimidos (Costa, 2008). O mesmo fato observa-se na casuística dos casos que envolvem o gênero Candida, que compõe a microbiota do homem e de animais hígidos, entretanto adquire caráter oportunista devido a distúrbios nas proteções física, química e imunológica (Staib, 1962). Devido à alta concentração de fungos leveduriformes em locais com acúmulo de excretas de aves, 
principalmente em áreas urbanas, acrescida da severidade da criptococose e de outras enfermidades fúngicas causadas por outras leveduras associadas, há um crescente interesse na relação da tríade, composta por aves, excretas ambientais e zoonoses. Entre 1980 e 1999, o Ministério da Saúde verificou que 4,5\% de infecções oportunistas em portadores do vírus da imunodeficiência humana (HIV) foram provocadas por Cryptococcus (Faganello, 2008). Pelo exposto, objetivou-se verificar em excretas ambientais de pombos, acumuladas em assoalhos de praças, escolas e vias públicas, a presença de fungos leveduriformes com potencial patogênico, como Cryptococcus spp. e associados, bem como identificá-los, utilizando testes bioquímicos e caracterização molecular, por meio da reação em cadeia da polimerase (PCR).

\section{MATERIAL E MÉTODOS}

Araçatuba localiza-se na região noroeste do estado de São Paulo, a uma latitude $21^{\circ} 12^{\prime} 32^{\prime \prime}$ sul e a uma longitude $50^{\circ} 25^{\prime} 28^{\prime \prime}$ oeste, com altitude de $390 \mathrm{~m}$, e de clima tropical semi úmido, com média pluvial de $1.267 \mathrm{~mm} \mathrm{e}$ temperatura média de $23.8^{\circ} \mathrm{C}$, (CEPAGRI, 2015).

Para verificar a ocorrência de leveduras com caráter patogênico enfocando principalmente Cryptococcus spp. e leveduras associadas, foram colhidas 100 amostras de excretas ambientais de pombos provenientes de praças, parques e calçadas da cidade de Araçatuba, SP. Os pontos de coleta foram determinados a fim de se obter um universo amostral representativo de toda a área da cidade. As amostras foram rasteladas dos locais, identificadas e acondicionadas em recipientes estéreis, com tampa de rosca, e imediatamente encaminhadas ao laboratório de Bacteriologia e Micologia da Faculdade de Medicina Veterinária, Unesp/Araçatuba.

As amostras foram processadas em câmara de fluxo laminar, onde $1 \mathrm{~g}$ da amostra foi macerado, utilizando-se pistilo e gral. Posteriormente, o material foi colocado em um frasco Erlenmeyer de $125 \mathrm{~mL}$, contendo $50 \mathrm{~mL}$ de salina estéril a $0,9 \%$; a essa solução foi acrescido cloranfenicol a $0,04 \%$. Após vedação do frasco com parafilm $\AA$, a amostra foi agitada vigorosamente em vórtex por cinco minutos. Em seguida, a solução foi mantida em repouso por um período de 30 minutos. Posteriormente, $1 \mathrm{~mL}$ do sobrenadante foi aspirado e acondicionado em tubo tipo Eppendorf, para posterior semeadura de $0,1 \mathrm{~mL}$ da solução com alça de Drigalski, em placas de Petri contendo ágar Niger e Sabouraud com 4\% dextrose. As placas foram identificadas e incubadas à temperatura de $30^{\circ} \mathrm{C}$ e à temperatura ambiente, respectivamente. A leitura ocorria diariamente, e as amostras foram repicadas conforme necessário para obtenção de isolados puros.

No meio de cultura ágar Niger, as colônias de $C$. neoformans var neoformans e de C. neoformans var gattii adquirem uma coloração marrom, devido à atividade fenoloxidase em presença de substrato contendo compostos fenólicos. As colônias com crescimento sugestivo de levedura foram repicadas, em placas contendo ágar Niger e Sabouraud dextrose a 4\% para identificação e manutenção da amostra até a obtenção de colônias puras.

Todas as colônias leveduriformes foram submetidas à coloração com tinta nanquim e lactofenol - azul algodão -, para a análise morfológica das estruturas fúngicas. As colônias identificadas do gênero Cryptococcus foram submetidas a testes bioquímicos e à caracterização molecular para a identificação da espécie.

Para análise da termotolerância, as amostras foram repicadas em ágar Sabouraud, mantidas a $37^{\circ} \mathrm{C}$ por sete dias

A utilização do meio ureia-ágar-base (Christensen, 1946),permite observar à hidrólise da ureia com produção de amônia e alcalinização do meio, causando alteração do indicador de $\mathrm{pH}$ de neutro para básico, evidenciando-se, assim, uma coloração de tom róseo intenso. Os isolados foram repicados nesse meio e incubados a $30^{\circ} \mathrm{C}$ por cinco dias.

Para diferenciar as espécies de C. neoformans e C. gattii, foi utilizado o meio canavanina-glicinaazul de bromotimol (CGB) (Know-Chung et al., 1982). As colônias de C. gattii utilizam a glicina como fonte de carbono e nitrogênio e são resistentes à canavanina, mostrando uma coloração azul-cobalto, enquanto $C$. neoformans não demonstra mudança na coloração do meio. Os isolados foram repicados em meio CGB e 
incubados a $30^{\circ} \mathrm{C}$ por até cinco dias, observandose diariamente a coloração do meio.

Com a utilização de alça bacteriológica, uma porção do isolado de levedura foi suspendida para um tubo de $1,5 \mathrm{~mL}$ contendo $500 \mu \mathrm{L}$ de solução de Tris-EDTA $(10 \mathrm{mM}$ Tris, $1 \mathrm{mM}$ EDTA). Para efetivar a extração do DNA, a mistura foi aquecida a $95^{\circ} \mathrm{C}$ por três minutos e congelada em nitrogênio líquido por um minuto, perfazendo um ciclo realizado cinco vezes, com uma centrifugação final a $16.100 \mathrm{~g}$, por um período de cinco minutos.

Foram utilizados dois primers específicos para região do espaçador transcrito interno (ITS-2) de leveduras (De Baere et al., 2002), um senso (CRYITS2F) e um antissenso (CRYITS2R) com as sequências respectivas GTGAATCATCGAATCTTTGAAC e TCCTCCGCTTATTGATATGC (Invitrogen, São Paulo, Brasil). O perfil de ciclagem consistiu de 35 ciclos, sendo $94^{\circ} \mathrm{C} / 2$ minutos $(1 \mathrm{X})$, $94^{\circ} \mathrm{C} / 45$ segundos, $61^{\circ} \mathrm{C} / 1$ minuto e $72^{\circ} \mathrm{C} / 2$ minutos (35X) e uma extensão final a $72^{\circ} \mathrm{C}$ por 10 minutos. $\mathrm{O}$ fragmento amplificado foi analisado em gel de agarose a $1 \%$, e a banda visualizada, removida e purificada para posterior sequenciamento. $\mathrm{O}$ fragmento resultante da PCR para o gene da ITS-2 foi purificado utilizando-se o kit de purificação "QIAquick Gel Extraction Kit” (Qiagen $\left.{ }^{\circledR}\right)$ e foi submetido a sequenciamento utilizando-se o "ABI Prism ${ }^{\circledR}$ Dye Terminator Cicling Sequence Kit” (Applied Biosystems). As reações de sequenciamento foram realizadas nas duas direções, utilizando-se os primers da PCR.

\section{RESULTADOS E DISCUSSÃO}

Os resultados mostraram que das 100 amostras processadas, 27 apresentaram crescimento de pelo menos um tipo de levedura com caráter patogênico. A maior ocorrência foi para Rhodotorula rubidae, $17 \%$ das amostras positivas, seguido por Cryptococcus neoformans var. neoformans, $8 \%$, e Candida albicans, $7 \%$. Ressalta-se que, em cinco cultivos, houve o crescimento associado Cryptococcus spp. e Rhodotorula sp. e outros dois de Candida sp. e Rhodotorula sp.

A cidade de Araçatuba não é considerada área endêmica para a Criptococose, mas a permanência de microfocos em áreas públicas aumenta os riscos à exposição. Outro fator importante, além de agravante em termos de saúde pública, é a infecção por C. neoformans var. gatti, por se comportar como patógeno primário, não estando associado à imunodeficiência dos hospedeiros, sendo observada sua ocorrência em paciente imunocompetente (Filiú et al., 2002), diferentemente da infecção pelo $C$. neoformans var. neoformans, que se encontra associada à imunossupressão. As amostras do presente estudo foram positivas para o isolamento de Cryptococcus neoformas var. neoformans, semelhantemente a Baroni (2001) e diferentemente de Soares et al. (2005), que examinaram 79 amostras de excretas de pombos da cidade de Santos e encontraram 13,9\% de cultivos positivos para $C$. neoformans var. grubii. A origem do Criptococcus spp. nessas excreções permanece obscura, uma vez que o fungo não tem sido isolado do trato gastrintestinal de aves, onde, inclusive, teria dificuldade em sobreviver à competição microbiana (Filiú et al., 2002). De acordo com Reolon et al. (1998), excretas secas oferecem um substrato mais favorável devido à menor quantidade de bactérias, diminuindo a competição, o que pode resultar em melhor crescimento de $C$. neoformans var. neoformans nesse substrato.

Pode-se inferir que Araçatuba não apresenta condições climáticas favoráveis à permanência prolongada do fungo no ambiente, por apresentar altas temperaturas e baixa umidade do ar, entretanto é plausível acreditar que haja a ocorrência da infecção, posto que existe uma grande quantidade de excreções de aves, facilmente observadas em vias e locais públicos.

A temperatura elevada associada à baixa umidade e à exposição direta à radiação solar são fatores que podem ter contribuído para $o$ resultado reduzido dos isolamentos para Cryptococcus, uma vez que altas temperaturas $\left(30^{\circ} \mathrm{C}\right)$ são menos favoráveis à sobrevivência do fungo (Oliveira et al., 2005). Quintero et al. (2005) ainda atribuem a altitude entre 2000 e $3000 \mathrm{~m}$ e o clima frio como fatores favoráveis ao desenvolvimento do Cryptococcus.

Isto posto, ainda se ressalta a capacidade de resistência dos fungos no ambiente, 
permanecendo viável mesmo em situações adversas. Baroni (2001), em um estudo realizado na cidade de Rio de Janeiro, analisou 219 amostras de excretas de pombos provenientes de diversos ambientes, como torres de igreja, solo, insetos, ovos e ninho, e encontrou $37,8 \%$ de isolamentos positivos para Cryptocococcus neoformans var. neoformans. O referido autor também relacionou as condições climáticas, como temperatura moderada do ar, como um fator favorável à ocorrência do agente no ambiente. Alguns autores têm descrito a presença do Cryptococcus neoformans var. neoformans em excretas de pombos em igrejas, ruas e praças, enfatizando o provável risco ao público (Filiú et al., 2002; Reolon et al., 2004).

A tipificação molecular tem sido uma ferramenta importante em estudos epidemiológicos buscando um maior conhecimento sobre a dinâmica do ciclo ecológico do fungo. $\mathrm{O}$ método utilizado para a tipagem de C. neoformans, descrito por Meyer et al. (2003), baseia-se na análise dos perfis de restrição enzimática, que permite diferenciar os isolados em oito tipos moleculares: VNI (correspondente a C. neoformans var. grubii, sorotipo A); VNII (também correspondente a C. neoformans var. grubii, sorotipo A); VNIII (estirpes híbridas de sorotipo A/D); VNIV (correspondente a $C$. neoformans var. neoformans, sorotipo D); e VGI, VGII, VGIII e VGIV (correspondentes a $C$. neoformans var. gattii, sorotipos $\mathrm{B}$ e $\mathrm{C}$ ).

A caracterização do sequenciamento da região do espaçador transcrito interno 2 (ITS-2) foi compatível com oito amostras positivas para Cryptococcus neoformans var. neoformans (Tab. 1). Normalmente, a maioria dos Cryptococcus isolados são haploides, no entanto alguns isolados diploides ou aneuploides podem levar a fenótipos instáveis, que podem ser recombinantes ou híbridos (Know-Chung e Varma, 2006).

A detecção de sequências gênicas por meio de DNA, pela PCR em infecções fúngicas, vem sendo apresentada como promessa de diagnóstico na identificação desse agente (Costa, 2007).
Tabela 1. Tipificação molecular das oito amostras positivas para Cryptococcus neoformans

\begin{tabular}{ccc}
\multicolumn{4}{c}{ Cryptococcus neoformans } \\
\hline Tipo molecular & Sorotipo & Variedade \\
\hline VNI & A & Grubii \\
VNII & A & Grubii \\
VGI & B & Gatti \\
VGII & B & Gatti \\
VGIII & B & Gatti \\
VGIV & C & Gatti \\
VNIV & D & Neoformans \\
VNIII & AD & Híbrido \\
\hline
\end{tabular}

A ocorrência de $7 \%$ para Candida sp., apesar de pequena, é importante, por se referir a uma levedura que infecta o homem e várias espécies animais, incluindo as aves (Godoy, 2007). A ocorrência de Candida sp. nas fezes de aves pode ser indicativo de imunossupressão das aves, por ser um fungo de caráter oportunista (McCullage, 1996), porém as amostras foram colhidas do solo, portanto essa levedura pode ter origem ambiental não necessariamente relacionada com a ave.

Em um levantamento literário sobre infecções por Rhodotorula spp. em humanos, verificou-se que $40 \%$ dos quadros de infecção ocorrem associados à imunossupressão. Outros fatores predisponentes observados foram neoplasias, doenças hematológicas e transplantes. A espécie mais isolada foi $R$. mucilaginosa, seguida por $R$. glutinis. Foram relatados dois casos de endoftalmite, cujo agente etiológico era $R$. minuta (Tuon e Costa, 2008).

Perniola et al. (2006) relataram a ocorrência de um surto de infecção por $R$. mucilaginosa em uma unidade de tratamento intensivo neonatal, na Itália. Todos os neonatos acometidos apresentavam trombocitopenia, e, em $50 \%$, com concomitante de neutropenia. Apesar de isolados, não foram identificadas as espécies de Rhodotorula e Candida presentes nas amostras, por não ser o foco principal do presente estudo.

Sendo assim é necessário repensar sobre algumas medidas adotas como preventivas contra a permanência de fungos com potencial patogênico no ambiente, constituindo-se em focos.

O estudo realizado por Santos et al. (2009) sugere procedimentos rotineiros de limpeza e 
desinfecção de locais onde há acúmulo de fezes, pois essas medidas são consideradas eficazes no controle epidemiológico de Cryptococcus neoformans, contudo tais medidas não são realizadas com eficiência em locais públicos de Araçatuba, SP, onde há acúmulo de excretas de aves, tornando esses locais possíveis focos de infecção.

Em excretas de pombos localizadas em ambientes urbanos de acesso público, foi possível o isolamento de Cryptococcus spp., Rhodotorula spp. e Candida spp., gêneros de leveduras oportunistas com potencial patogênico. Foram identificadas por meio da técnica da PCR e do sequenciamento de oito amostras positivas para Cryptococcus, sendo dois deles identificados como C. neoformans var. grubii, um como C. neoformans var. neoformans, outros quatro positivos para $C$. neoformans var. gatti, além de um isolado híbrido.

\section{CONCLUSÃO}

Pelo exposto, concluiu-se a existência de fontes ambientais na cidade de Araçatuba, SP, que constituem microfocos para Cryptococcus neoformans var. neoformans e leveduras correlatas com potencial de contaminação, seja pela dispersão de propágulos aerossolizados no ambiente carreados pela ação do vento, seja pela inalação das partículas, o que acarreta doenças no homem e em animais, representando risco populacional. Isto posto, enfatiza-se a necessidade da implantação de medida preventiva, como a higienização de locais de acesso público, a fim de diminuir os focos de exposição.

\section{REFERÊNCIAS}

BARONI, F.A. Ocorrência de Cryptococcus neoformans em excretas de pombos localizadas em torres de igrejas na cidade do Rio de Janeiro: fatores de virulência e sensibilidade aos antifúngicos. 2001. 232f. Tese (Doutorado em Ciências Biomédicas) - Instituto de Ciências Biomédicas da Universidade de São Paulo, São Paulo.

CASADEVALL, A.; PERFECT, J.R. Cryptococcus neoformans. Washington ASM Press; p.541, 1998.
CHRISTENSEN, W.B. Urea decomposition as a means of differentiating Proteusand paracolon cultures from each other and from Salmonella and Shigella types. J. Bacteriol., v.52, p.461-466, 1946.

COSTA, A.K.F. Leveduras associadas à cloaca e a excrementos de pombos (Columbia livia): um enfoque especial para os aspectos micológicos de Cryptococcus spp. 2007. 122f. Dissertação (Mestrado em Ciências Veterinarias). Universidade Estadual do Ceará, Faculdade de Veterinária, Fortaleza, Ceará.

DE BAERE, T.; CLAEYS, G.; SWINNE, D. et al. Identification of cultured isolates of clinically important yeast species using fluorescent fragment length analysis of the amplified internally transcribed rRNA spacer 2 region (ITS2). BMC Microbiol., v.2, p. 21, 2002.

ELLIS, D.H.; PFEIFFER, T.J. Natural habitat of Cryptococcus neoformans var. gatti. J. Clin Microbiol., v. 28, p. 1642-1644, 1990.

FAGANELLO, J. Estudo da variabilidade $e$ diferenças morfológicas entre as espécies Cryptococcus neoformans e Cryptococcus gattii por análise de diferença representacional $e$ microscopia eletrônica de varredura. 2008. $181 \mathrm{f}$. Tese (Doutorado em Biologia Celular e Molecular). Universidade Federal do Rio Grande do Sul, Porto Alegre, Rio Grande do Sul.

FILIÚ, W.F.O; WANKE, B.; AGUENA, S.M. et al. Cativeiro de aves como fonte de Cryptococcus neoformans na cidade de Campo Grande, Mato Grosso do Sul, Brasil. Rev. Soc. Bras. Med. Trop., v.35, p.591-595, 2002.

FORTES, A.T.; ASSATO, M.S.; FORTES, S. et al. Meningoencefalite por Cryptococcus neoformans var gattii em indígena hiv negativo. 1999. Disponível em:< http://neuroc99.sld.cu/ text/meningoencefalite.htm $>$. Acessado em: 28 nov. 2013.

GODOY, S.N. Psittaciformes (Araras, papagaios, periquito). In: CUBAS, Z.S.; SILVA, J.R.; CATÂODIAS, J.L. (Ed). Tratado de animais selvagens. Medicina veterinária. São Paulo: ROCA, 2007. p.222-251

KNOW-CHUNG, K.J.; BENNETT, J.E. Medical Mycology. Philadelphia: Lea e Figiber; 1992. $866 \mathrm{p}$. 
KNOW-CHUNG, K.J.; POLACHECK, I.; BENNETT, J.E. Improved diagnostic mediumfor separation of Cryptococcus neoformans var. neoformans (serotype A and D) and Cryptococcus neoformans var. gattii (serotype B and C). J. Clin. Microbiol., v.15, p.535-537, 1982.

KWON-CHUNG, K.J.; VARMA, S.A. Do major species concepts support one, two or more species within Cryptococcus neoformans? FEMS Yeast Res., v.6, p.574-587, 2006.

LEVITZ, S.M. The ecology of Cryptococcus neoformans and the epidemiology of cryptococcosis. Rev. Infect. Dis., v.13, p.11631169, 1991.

MAIA, D.C.B.S.C. Leveduras isoladas do trato gastrintestinal de calopsitas (Nymphicus hollandicus): determinação da microbiota $e$ análise fenotípica. 2009. 86f. Dissertação (Mestrado em Ciências Veterinárias). Universidade Estadual do Ceará, Faculdade de Veterinária, Fortaleza, Ceará.

MARINHO, M.; TÁPARO, C.V.; SILVA, B.G. et al. Microbiota fúngica de passeriformes de cativeiros da região noroeste do estado de São Paulo. Vet. Zootec., v.17, p.288-292, 2010.

MCCLUGGAGE, D.M. Zoonotic disorders, in Diseases of Cage and Aviary Birds. Third Edition, eds Rosskopf WJ and Woerpel RW. Williams and Wilkins Baltimore USA. p.535547.

MEYER, W.; CASTANEDA, A.; JACKSON, S. et al. Molecular typing of IberoAmerican Cryptococcus neoformans isolates. Emerg. Infect. Dis., v.9, p.189-195, 2003.

OLIVEIRA, I.A.; NOBRE, M.O.; FERREIRO, L. Pesquisa de criptococcose em cães atendidos no Hospital de Clínicas Veterinárias da UFRGS, Porto Alegre, Brasil. Acta Sci. Vet., v.33, p.253$258,2005$.

PERNIOLA, R.; FANESCHI, M.L.; MANSO, E. et al. Rhodotorula mucilaginosa outbreak in neonatal intensive care unit: microbiological features, clinical presentation, and analysis of related variables. Europ. J. Clin. Microbiol. Infect. Dis., v.25, p.193-196, 2006.
QUEIROZ, J.P.A.F.; SOUZA, F.D.N.; LAGERA, M. et al. Criptococcose - uma revisão Bibliográfica. Acta Vet. Basílica, v.2, p.32-38, 2008.

QUINTERO, E.; CASTAÑEDA, E.; RUIZ, A. Environmental distribution of Cryptococcus neoformans in the department of CundinamarcaColombia. Rev. Iberoam. Micol., v.22, p.93-98, 2005.

REOLON, A.; PEREZ, L.R.R.; MEZZARI, A. Prevalência de Cryptococcus neoformans nos pombos urbanos da cidade de Porto Alegre, Rio Grande do Sul. J. Bras. Patol. Med. Lab., v.40, p.293-298, 2004.

SANTOS, L.L.; FERREIRA, F.M.; LOPES, S.F. et al. Pesquisa de Cryptococcus neoformans e Candida spp. em excretas de psitacídeos e passeriformes cativos. Arq. Cienc. Vet. Zool. Unipar, v.12, p.5-9, 2009.

SILVA, J.O.; CAPUANO, D.M. Ocorrência de Cryptococcus spp e de parasitas de interesse em saúde pública, nos excretas de pombos na cidade de Ribeirão Preto, São Paulo. Brasil. Rev. Inst. Adolfo Lutz (Impr.), v.67, p.50-54, 2008.

SOARES, M.C.B.; PAULA, C.R.; DIAS, A.L.T. et al. Environmental straits of Cryptococcus neoformans variety grubii in the city of Santos, SP, Brazil. Rev. Inst. Med. Trop. São Paulo, v.47, p.31-36, 2005.

STAIB, F. Cryptococcus neoformans and Guizotia abyssinica (syn. G. oleifera D.C.) (Farbreaktion fur C. neoforimans). Z. Hyg. v.148, p.466-475, 1962.

TENCATE, L.N.; TÁPARO, C.V.; CARVALHO, C. et al. Estudo da Microbiota fúngica gastrintestinal de morcegos (Mammalia , chiroptera) da região noroeste do estado de São Paulo: potencial patogênico. Braz. J. Vet. Res. An. Science, v.49, p. 146-152, 2012.

TORRES-RODRIGUES, J.M.; MENDOZA, M.H.; ALVARADO-RAMIREZ, E. et al. Cryptococcosis by Cryptococcus gattii in immunocompetent goats in Spain and review of the literature. Acta Sci. Vet., v.34, p.245-53, 2006.

TUON, F.F.; COSTA, S.F. Rhodotorula infection: a systematic review of 128 cases from literature. Rev. Iberoam. Micol., v.25, p.135-140, 2008. 